This is a pre-print of an article published in Journal of Family Therapy. The definitive publisher-authenticated version for Nolte, L (2007) White is a colour too: engaging actively with the risks, challenges and rewards of cross-cultural family therapy training and practice, Journal of Family Therapy, 29: 378-388 can be found here: http://onlinelibrary.wiley.com/doi/10.1111/j.1467-6427.2007.00406.x/abstract .

\title{
White is a colour too: engaging actively with the risks, challenges and rewards of cross-cultural family therapy training and practice
}

\section{Lizette Nolte}

Due to increased global mobility and displacement there is a growing cultural diversity within therapeutic encounters between therapists and clients. Literature on cross-cultural therapy traditionally focuses on the culture of clients. However, due to recent theoretical shifts in the family therapy field, the importance of including the culture of therapists in the discourse about crosscultural therapy has been highlighted. Drawing on the experience of the author, as therapist, trainee and trainer, as well as recent developments in the literature, this paper reflects on crosscultural training and practice within family therapy in Britain. The author argues that white is a colour too, thus challenging 'white' therapists not to leave thinking about and addressing crosscultural issues in family therapy to their colleagues 'of colour', but to actively engage with the risks and uncertainties of cross-cultural learning and practice. Ways to facilitate this process are suggested. In particular a multi-dimensional approach that allows for complexity and contradiction is promoted and the potential of using the personal life experiences of therapists as a safe, nonpathologizing training tool is discussed.

\section{Introduction}

Through ever-increasing global mobility and displacement, therapists in Britain are faced today with ever-greater cultural diversity in their client groups. Moreover, these therapists themselves form a culturally diverse group including many first- and second-generation migrants. Now, more than ever, the therapeutic encounter may be seen as a 'meeting of cultures' (Pare', 1996). In the literature on cross-cultural therapy and within family therapy training itself, the focus is often still exclusively on the culture of the client. The therapist's own culture often remains a 'hidden' factor in the therapeutic encounter (Di Nicola, 1997).

Some time ago I carried out a small qualitative research project looking at the cultural selves of therapists (Nolte, 2000). I interviewed a group of family therapists who have migrated to Britain. This study was the inspiration for the exploration of ideas that follow in this paper. In the study two themes running through the interviews particularly struck me. First, the therapists from black and ethnic minority backgrounds described many experiences of racism, also specifically within collegial relationships and professional contexts. This powerfully challenged me to look at how we manage our cultures and ethnicities among ourselves within the community of family therapists in Britain. Second, there was a creativity among the therapists I interviewed in their descriptions of how they used their migration experiences, their 'sameness' and differences, when working with families within their clinical contexts - this made me curious as to what inhibits or enhances creativity within crosscultural clinical work. 
This paper describes the development of my ideas on these two themes and draws on my own personal and professional experience and recent developments in the family therapy literature to reflect on the self of the therapist within cross-cultural therapy and training. I wish to place the focus particularly on white therapists.

\section{'Whiteness' within the cross-cultural debate - white is a colour too}

Since the family therapy field has embraced postmodern and social constructionist frameworks, contextual issues in the lives of not only our clients but also ourselves as family therapists have been high- lighted. This has brought issues of culture, power and the therapeutic relationship more into focus. However, despite this shift and a greater focus on the 'self' of the therapist, the focus in the cross-cultural literature has mostly remained on the culture of the client, including how the therapist can be aware, knowledgeable, sensitive and competent in working with clients from minority ethnic groups. Little has been written about the culture of the therapist, especially white cultures, and the impact thereof on the therapeutic relationship and therapeutic work.

Historically, 'white' therapists and researchers have often made themselves guilty of studying the 'other' (Kitzinger and Wilkinson, 1996) from a normative position. Within the literature on cross- cultural therapy concerns have been raised that discussions focus on 'otherness' in ways that set white Western cultures as the same and the norm, and emphasize deficits rather than adaptive strengths in other cultures (Eichstedt, 2001; Laird, 1998). It is a challenge in cross-cultural thinking to move away from a position of difference as something 'inside' the other. Not only is difference often placed 'in' the other, but value is ascribed to these differences, thus maintaining the power of the dominant group to define what is normative or 'normal'.

However, some writers have emphasized the importance of cultural identity (including values, beliefs and perceptions) and personal cultural awareness (including assumptions, attitudes and prejudices) of therapists themselves (e.g. Barratt et al., 1999; Hardy \& Laszloffy, 1995; Pare', 1996). This requires a process of reflection, engaging with these issues in a more personal and self-reflective way. In this regard, the frame presented by Patel et al. (2000) that difference may be seen as 'a relational term', as something that exists between people rather than inside an individual, is helpful. These authors challenge us to take account of our own culture and that of our profession in a more personal way.

\section{Making it personal - risk-taking in cross-cultural training and therapy}

A more personal positioning implies taking personal risks. Although there are some important exceptions where therapists from different white cultures (see e.g. Gorell Barnes, 2002; Mason and Sawyerr, 2002; Miller and Thomas, 1994) have made very valuable contributions relating to ethnicity and culture that have powerfully shaped the thinking in the field, much of this risk-taking has perhaps for too long been largely left to black and minority ethnic therapists. While training as a family 
therapist a conflict situation developed between myself and a close colleague when I asked the colleague for advice about an African family (the colleague defined herself as black British). I thought I was being respectful, acknowledging an inability to understand 'what it was like' and acknowledging her lived experience and her professional history (e.g. facilitating workshops on 'race' and culture) and special interest. The colleague felt that I needed to do my own thinking around issues of ethnicity and not treat her as the 'black therapist', representing all 'black' people. At the time we both felt hurt and misunderstood. Nevertheless, in culturally mixed training and working contexts this experience is not that unusual (see e.g. AnaneAgyei et al., 2002).

Unfortunately this incident was not engaged with by the trainers on the course and an opportunity was missed for work that would have been potentially useful for both trainees. On reflection, the colleague made a valuable point. White therapists have the responsibility, the obligation, the right and the ability to do their own thinking when it comes to cross-cultural issues (Pewewardy, 2004). This does not mean, however, that there is not much to learn, but first we have to show willingness to take risks ourselves (Mason, 2005a, 2005b). This of course is a very vulnerable position to be in (Cooper, 1997), but why should white therapists be excluded or protected from this vulnerable position just because of our whiteness? As Patel and colleagues state in relation to trainees from black and ethnic minority backgrounds always being put in the expert position in relation to issues of 'race' and culture: 'The inevitable costs attached to this expert position may far outweigh any benefits' (Patel et al., 2000, p. 17). Perhaps this burden could be shared more fairly. I will now explore what might get in the way of white therapists engaging with this process.

\section{Deconstructing whiteness}

It is only recently that there has been awareness and deconstruction of the cultural identities of white families and therapists (e.g. Barratt et al., 1999; Eichstedt, 2001; McIntosh, 1998). As a white person who has migrated, I am very aware of being different, and being seen as different, despite having a similar skin colour to that of people of the host culture. More recently some authors have written about the need to not see 'white' cultures, including the host culture(s), as a homogenous group, but to differentiate between different white cultural groups (Myers et al., 2005). This point has mostly been made by therapists who do not define themselves as white (with some exceptions; e.g. Gorell Barnes, 2002), raising the question of whether there might be reluctance or lack of awareness of the need among white therapists to explore their differences (Khan, 2002; Thomas, 2002). It is my experience that white therapists not only often take a normative position, but they also often view themselves as 'culture-free', or 'culture-poor', finding it difficult to define themselves culturally or to deconstruct their culture. However, white is a colour too, and culture, ethnicity and 'otherness' are things we all have. It is the responsibility of therapists who define themselves as 'white' to begin to engage more actively with this process, allowing for difference to emerge, thus challenging and undermining a normative position and developing rich, complex and multi-dimensional descriptions of our different cultures. 


\section{A need to reflect on dominance}

For white therapists to engage in this process we need first to reflect on what it means to be part of a dominant group and to acknowledge the privilege, power and assumed superiority, discrimination and racism against others that have come with this position (McIntosh, 1998; Patel et al., 2000). From experience I know that this can be a very painful and uncomfortable, but in my view essential, process.

However, this is also a process that has the potential to be counter-productive, achieving the opposite of what it intends by leaving therapists or trainees feeling ashamed, guilty and uncomfortable in a way that makes them shy away from confronting issues of ethnicity and culture. This could manifest itself, for example, through avoiding training events on cultural issues or speaking with colleagues in supervision about cultural issues, or avoiding developing co-working relationships where cultural learning can take place. This is an unhelpful and at worst dangerous position for both family therapists and the families who come to us for therapy.

\section{A balanced perspective}

One factor that can act to counterbalance this distancing and disengaging is for white cultures, like all cultures, to be looked at multi- dimensionally. Unpacking white cultures should include many different facets and not only focus on the implications of dominance, repression and racism, however important these issues are. Potentially their culture would have provided the white therapist or trainee with their sense of self and belonging, with their mother tongue, and it potentially includes their most intimate childhood experiences, their family traditions and rituals, that which feels most true and authentic to them. All these aspects should be included, valued and respected in their reflection on their own culture, thus allowing their particular white culture to be multi-dimensional, rich and complex (like all cultures). Gorell Barnes (2002) states that a starting point for training and becoming competent in cross-cultural therapy is a context in which differences themselves, rather than conformity, can be acknowledged and valued.

\section{Implications for teaching and training in family therapy}

Much change has happened in relation to the acknowledgement of ethnicity and culture on training courses. However, it is worrying that family therapists in Britain continue to express unease that issues of ethnicity and culture are not given enough focus in training (e.g. Singh, 2004). It is important to address ethnicity and culture in training courses in a meaningful way, including treating the culture of the therapist as central to the learning. An example of this would be the use of cultural genograms (Hardy and Laszloffy, 1995). The culture of all trainees, including white trainees, should be included in the discussions during training. 
Formal and expert knowledge is often valued within the therapeutic world, whereas local knowledges and life experiences of therapists are marginalized in their training and supervision (Krause, 2002). White (1997) suggests that this marginalization of the personal could contribute to therapists experiencing themselves as unskilled and not knowledgeable, and this could lead to a lack of confidence, also when working cross-culturally. Although an approach that focuses more on the personhood of the therapists within their training holds much possibility, there are also potential difficulties in such a process (Barratt et al., 1999; Miller and Thomas, 1994), and little has been written about this.

Such family therapy training would challenge our sense of our own neutrality and egalitarianism, place the spotlight on our own racism and would require us to tolerate and contain such conversations. This could be a liberating process, but also a challenging one of examining one's personal and professional narratives (Khan, 1998), and of remaining respectful of the diversity of realities which constitute our own lives and the lives of our clients and colleagues (Jones, 1998).

One way of allowing such training to be experienced as safe and helpful is highlighted by White (1997). He suggests that therapists should reclaim and privilege the significant historical and local associations of their lives. He states that this 'remembering' could contribute to therapists experiencing themselves as 'knowledged' and skilled in their work, and that this could be empowering and increase therapists' confidence. Drawing on this narrative paradigm, it is my view that relating these conversations to particular life experiences of therapists or trainees, rather than a distant approach that draws more on theory, instruction and the culture of the 'other', would be helpful. I have, for example, asked trainees to remember a situation where they have felt marginalized, excluded or misunderstood within an experiential exercise related to work on difference, and experienced that this allowed for a very rich and personal reflection and learning to take place. This would also allow for a very personal and rich reflection on being different and on the difference of others, potentially translating into creativity within the therapeutic context.

This more personal approach to training can counteract the danger of 'political correctness' or the 'add-on' nature of discussions about culture within training. The danger of a 'political correctness focus' in training is that it can lead to potential 'idealizing' (Patel et al., 2000). Furthermore, it could lead to potential tentativeness. Trainees could become overly careful not to offend, leading to what Gunaratnam (2007) has called 'the discrimination of the constraint in risk-taking'. This 'constraint in risk-taking' inhibits the very openness, curiosity and context of safety that is required for developing true competence in cross-cultural work (Dyche and Zayas, 1995; Falicov, 1995). It is essential for trainers to work to overcome this constraint in trainees, rather than re-enforce it.

The danger of this form of discrimination is that it is an invisible discrimination. Trainees and therapists would describe themselves as anti-racism and would experience themselves as respectful and as having 'good intentions'. However, often unknowingly, they will deprive their clients from black and ethnic minority 
backgrounds of the feeling of being at ease, of being understood and of a warm therapeutic relation- ship, through their 'constraint in risk-taking'. It is therefore essential that our training enables us to become comfortable in cross-cultural work. I will now explore how this might be promoted during training.

\section{Developing a language in cross-cultural training and therapy}

Developing a language for cross-cultural work is one of the essential parts of training and developing competence and confidence in working cross-culturally. Often it is not knowing how to ask a question, what can be asked, how to describe a situation or family or cultural dilemma without offending or showing one's ignorance that gets in the way of cross-cultural learning, confidence and competence (Cardemil and Battle, 2003; La Roche and Maxie, 2003). This could lead to feelings of vulnerability, anxiety, confusion, dissonance and guardedness (Khan, 2002). It is likely that many therapists will leave current training courses with an intellectual appreciation of the salience of issues of ethnicity and culture in the therapy context and be motivated to be sensitive to these issues in their practice. This is not enough (Cardemil and Battle, 2003). One of the ways to overcome this dilemma is membership of a culturally mixed group where trust, openness and a non-blaming culture exists (see Mason and Sawyerr (2002) for a description of such a group). Thomas (2002) states that good therapeutic work within culturally mixed teams will only happen once team and personal development relating to ethnicity and culture have taken place. AnaneAgyei et al. (2002) describe the often painful nature of such a process and give guidelines for avoiding pitfalls, including assuming the good intentions of all and avoiding polarization.

Training courses provide natural opportunities with groups working together in an intimate way over a prolonged period of time - it is the responsibility of trainers to develop the culture of trust, openness and personal risk-taking in these groups for effective training to happen (Mason, 2005a, 2005b). More open conversations about difference should be facilitated, both formally and informally. Trainees experiencing being interviewed by and interviewing one another on issues of sameness and difference and having an opportunity to reflect on these experiences potentially create confidence in bringing these conversations into the clinical context.

Furthermore, if trainees are able to develop a language for thinking and talking about culture through their training, it would enhance the ongoing internal dialogue needed to continue to address and challenge racism in ourselves (Gorell Barnes, 2002) and to remain self-reflective. For this purpose the lived experiences of the group members, both outside and within the group, could be used. This could enable us to see the dilemmas presenting themselves in cross-cultural work as something to embrace rather than to withdraw from.

\section{Supervision}

It also seems particularly important that therapists and trainees have access to supervisors that explicitly consider their own and supervisees' cross-cultural 
positions and who provide a safe place for identifying and changing their professional assumptions and practices without pathologizing them.

\section{Future research}

Despite the fact that much is written on a regular basis about cross-cultural therapy, what happens in private, between therapist and client, between colleagues, in teams, often remains unspoken, thus preventing us from conceptualizing what we do that goes right or goes wrong, learning from these experiences and allowing others to benefit from it too (Mason and Sawyerr, 2002). Future studies should focus on process research, exploring what happens within cross-cultural therapy and within mixed cultural teams or working partnerships, for therapists to share their successes, failures, dilemmas, confusions and muddles, not only with client families but also with one another. This would open up for reflection what might be happening unintentionally and unknowingly.

Research into teaching courses and the place of 'race and culture' in personal and professional development modules is also urgently needed. These modules too often create artificial or theoretical contexts to which the trainees cannot relate, but miss the opportunities of the lived experiences of the trainees as a rich and relevant opportunity for learning. Research into what works well and what adds meaningfully to the development of cultural competence would contribute significantly to our thinking about training in this field.

\section{Conclusion}

Within the current climate in Britain of fear and bias towards minority ethnic groups, immigrants, asylum seekers and refugees, the profession should take note and seriously reflect on attitudes and actions within the profession and in wider society towards those who are delineated by these labels.

This paper wishes to promote an active engagement with the risks, challenges and rewards of cross-cultural learning within family therapy, especially also for therapists from different white cultures. My own experiences as researcher, trainee, trainer and clinician have continued to change my thinking in relation to cross-cultural work - it has led to a commitment to work towards finding ways to see the different aspects of my cultural identity and own migration as a resource, enriching my understanding, my sense of multi-dimensionality, looking for multiplicity in identity and sense of self, pushing myself to take risks while remaining open to be corrected and challenged. Holding on to these new perspectives now remains an ongoing challenge. Perhaps also, as we unpack our own white cultures more, we can become more competent in addressing issues of culture with our white client families - for them, white is a colour too. I also remind myself that when working with a family from a culture different to our own, their culture is just one aspect of who they are. As Khan (2002) points out, in cross-cultural therapy it is easy to get caught up in difference, losing sight of the many similarities. 


\section{Acknowledgements}

I would like to thank the six family therapists who participated in the original research project which challenged me to review my ideas about cross-cultural therapy. I would also like to thank Dr Pieter W Nel for his comments on an earlier draft of this paper.

\section{References}

Anane-Agyei, A., Lobatto, W. and Messent, P. (2002) The African Families Project: a black and white issue. In B. Mason and A. Sawyerr (eds) Exploring the Unsaid: Creativity, Risks, and Dilemmas in Working Cross-culturally. London: Karnac.

Barratt, S., Burck, C., Dwivedi, K., Stedman, M. and Raval, H. (1999) Theoretical bases in relation to race, ethnicity and culture in family therapy training. Context, 44: 4-12.

Cardemil, E. V. and Battle, C. L. (2003) Guess who's coming to therapy? Getting comfortable with conversations about race and ethnicity in psychotherapy. Professional Psychology: Research and Practice, 34: 278-286.

Cooper, A. (1997) Thinking the unthinkable: 'White liberal' defences against understanding anti-racist training. Journal of Social Work Practice, 8: 127-137. Di Nicola, V. (1997) A Stranger in the Family - Culture, Families and Therapy. New York: Norton.

Dyche, L. and Zayas, L. H. (1995) The value of curiosity and naivete' for the cross-cultural psychotherapist. Family Process, 34: 389-399.

Eichstedt, J. L. (2001) Problematic white identities and a search for racial justice. Sociological Forum, 16: 445-470.

Falicov, C. (1995) Training to think culturally: a multidimensional comparative framework. Family Process, 34: 373-388.

Gorell Barnes, G. (2002) Getting it right, getting it wrong: developing an internal discourse about ethnicity and difference. In B. Mason and A. Sawyerr (eds) Exploring the Unsaid: Creativity, Risks, and Dilemmas in Working Cross-culturally. London: Karnac.

Gunaratnam, Y. (2007) Workshop presented at Tavistock Clinic.

Hardy, K. V. and Laszloffy, T. A. (1995) The cultural genogram: a key to training culturally competent family therapists. Journal of Marital And Family Therapy, 21: 227-237.

Jones, E. (1998) Working with the 'self' of the therapist. Context, 40: 2-6. Khan, S. (1998) The therapeutic relationship: a dance of differences. Context, 40: 
Khan, S. (2002) Visible differences: individual and collective risk-taking in working cross-culturally. In B. Mason and A. Sawyerr (eds) Exploring the Unsaid: Creativity, Risks, and Dilemmas in Working Cross-culturally. London: Karnac.

Kitzinger, C. and Wilkinson, S. (1996) Theorising representing the other. In S. Wilkinson and C. Kitzinger (eds) Representing the Other: A Feminist and Psychology Reader. London: Sage.

Krause, I. (2002) Uncertainty, risk-taking, and ethics in therapy. In B. Mason and A. Sawyerr (eds) Exploring the Unsaid: Creativity, Risks, and Dilemmas in Working Cross-culturally. London: Karnac.

La Roche, M. J. and Maxie, A. (2003) Ten considerations in addressing cultural differences in psychotherapy. Professional Psychology: Research and Practice, 34: 180-186.

Laird, J. (1998) Theorising culture: narrative ideas and practice principles. In M. McGoldrick (ed.) Re-visioning Family Therapy - Race, Culture, and Gender in Clinical Practice. New York: Guilford Press.

Mason, B. (2005a) Relational risk taking and the therapeutic relationship. In C. Flaskas, B. Mason and A. Perlesz (eds) The Space Between: Experience, Context and Process in the Therapeutic Relationship. London: Karnac.

Mason, B. (2005b) Relational risk-taking and the training of supervisors. Journal of Family Therapy, 27: 298-301.

Mason, B. and Sawyerr, A. (2002) Introduction. In B. Mason and A. Sawyerr (eds) Exploring the Unsaid: Creativity, Risks, and Dilemmas in Working Cross-culturally. London: Karnac.

McIntosh, P. (1998) White privilege: unpacking the invisible knapsack. In M. McGoldrick (ed.) Re-visioning Family Therapy: Race, Culture and Gender in Clinical Practice. New York: Guilford Press.

Miller, A. and Thomas, L. (1994) Introducing ideas about racism and culture into family therapy training. Context, 20: 25-29.

Myers, C. A., Cricket, D., Meehan, M. and Negy, C. (2005) Caucasian Americans: the forging of an identity and culture. In C. Negy (ed.) Cross-cultural Psychotherapy: Towards a Critical Understanding of Diverse Clients. Reno: Bent Tree.

Nolte, L. (2000) The influence of migration on the cultural self of therapists and on their therapeutic work. Unpublished Masters thesis. 
Par'e, D. A. (1996) Culture and meaning: expanding the metaphorical repertoire of family therapy. Family Process, 35: 21-42.

Patel, N., Bennett, E., Dennis, M., Dosanjh, N., Mahtani, A., Miller, A. and Nadirshaw, Z. (eds) (2000) Clinical Psychology, 'Race' and Culture: A Training Manual. Leicester: BPS.

Pewewardy, N. (2004) The political is personal: the essential obligation of white feminist family therapists to deconstruct white privilege. Journal of Feminist Family Therapy, 16: 53-67.

Singh, R. (2004) Exploring culture in practice: a few facets of a training course. Journal of Family Psychotherapy, 15: 87-104.

Thomas, L. K. (2002) Ethnic sameness and difference in family and systemic therapy. In B. Mason and A. Sawyerr (eds) Exploring the Unsaid: Creativity, Risks, and Dilemmas in Working Cross-culturally. London: Karnac.

White, M. (1997) Narratives of Therapists' Lives. Adelaide: Dulwich Centre Publications. 